\title{
Geoquímica e geocronologia do granitóide Barra Alegre, faixa móvel Ribeira, Rio de Janeiro
}

\author{
Julio Cezar Mendes ${ }^{1,4}$, Patrícia Duffles Teixeira', Gabriel Corrêa de Matos ${ }^{1}$, Isabel Pereira \\ Ludka ${ }^{1}$, Felipe Fonseca Fernandes de Medeiros ${ }^{1,2}$ \& Ciro Alexandre Ávila ${ }^{3,4}$
}

\begin{abstract}
Resumo Na região serrana do Estado do Rio de Janeiro ocorrem unidades Neoproterozóicas pertencentes ao Segmento Central da Faixa Móvel Ribeira (Ciclo Brasiliano / Pan-Africano). Tratam-se preferencialmente de rochas ortoderivadas pertencentes ao Complexo Rio Negro e Batólito Serra dos Órgãos intercaladas a faixas de gnaisses paraderivados. O granitóide porfirítico Barra Alegre, aflorante entre os municípios de Bom Jardim e Trajano de Moraes, apresenta-se na forma de um corpo alongado NE-SW com composição monzogranítica a quartzo-monzonítica, estando envolto por rochas gnáissicas migmatíticas do Complexo Rio Negro e por gnaisses paraderivados correlacionáveis à Unidade Imbé. Duas litofácies foram definidas para o granitóide: 1 . fácies Barra Alegre, com textura porfirítica caracterizada por megacristais euhedrais a subedrais de microclina em matriz inequigranular xenomórfica granodiorítica/tonalítica, com xistosidade incipiente; 2. fácies Carijó, que ocorre preferencialmente nas zonas de borda do maciço e exibe conspícua xistosidade, apresentando fenocristais amendoados milimétricos de microclina em matriz granítica hipidiomórfica. Em ambas as litofácies a biotita é observada como fase máfica dominante. Minerais opacos, zircão, apatita e allanita são os principais minerais acessórios. Os principais marcadores da deformação são grãos de quartzo estirados, lamelas de geminação de plagioclásio e biotitas dobradas e recristalização de fenocristais e de grãos da matriz. Dados de campo e petrográficos permitiram interpretar que as rochas da fácies Carijó se formaram a partir da fácies Barra Alegre afetada por deformação heterogênea. Análises geoquímicas de rocha total, em conjunto com dados petrográficos e de campo, apontam uma assinatura cálcio-alcalina de alto $\mathrm{K}$, fracamente peraluminosa, e caráter tipo I para as rochas estudadas. São rochas moderadamente diferenciadas, de restrita variação de sílica e com padrões similares de ETR, enriquecidos em elementos terras raras leves. Dados geocronológicos obtidos pelo método de evaporação de zircão $\left.{ }^{207} \mathrm{~Pb} /{ }^{206} \mathrm{~Pb}\right)$ forneceram uma idade mínima de cristalização de $579 \pm 3 \mathrm{Ma}$ para o granitóide Barra Alegre, que leva a correlacionar esse corpo à fase sin-colisional do Segmento Central da Faixa Ribeira.
\end{abstract}

Palavras-chave: granitóide porfirítico, geoquímica, geocronologia Pb/Pb, Faixa Ribeira, Ciclo Brasiliano.

\begin{abstract}
Geochemistry and geocronology of the Barra Alegre granitoid, Ribeira fold belt, Rio de Janeiro Orthoderived rocks of the Rio Negro Complex and Serra dos Órgãos batholith are the dominant rocks of the mountain region of Rio de Janeiro State. They are locally associated with paraderived gneisses and belong to the Neoproterozoic Central Ribeira Belt. Between the cities of Bom Jardim and Trajano de Moraes, the NE-SW elongated Barra Alegre granitoid body occurs enveloped by migmatitic gneisses of the Rio Negro Complex and paraderived Imbé Unit. The granitoid is monzogranitic to quartz monzonitic in composition and shows a porphyritic texture. The size and shape of the microcline phenocrysts made possible the definition of two lithofacies in the granitoid body: 1. the Barra Alegre facies presents euhedral to subhedral megacrysts and weak schistossity; 2. the Carijó facies is characterized by augen texture and well developed schistossity. Biotite is the dominant mafic phase, while opaque minerals, zircon, apatite, and allanite are the main accessories minerals. Stretching quartz grains, fold biotite and plagioclase lamellae, and phenocrysts as well matrix recrystalization are the main deformation features. Based on field and petrographic evidences, the Carijó lithofacie is interpreted as a result of heterogeneous deformation from the Barra Alegre lithofacie. The geochemical characteristics along with petrographic and field data, point to a high-K calc-alkaline I-type, mildly peraluminous, character for these rocks. The restrict $\mathrm{SiO} 2$ variation indicates a moderately differentiated sequence. The rare earth element patterns of different rocks are similar, displaying LREE enrichment and a smooth Eu negative anomaly. $207 \mathrm{~Pb} / 206 \mathrm{~Pb}$ single zircon evaporation dating yielded a minimum crystallization age of $579 \pm 3$ Ma for the Barra Alegre granitoid. Such age is concordant with the syn-collisional episode established for the central segment of the Ribeira Belt.
\end{abstract}

Keywords: porphyritic granitoid, geochemistry, $\mathrm{Pb} / \mathrm{Pb}$ geochronology, Ribeira Belt, Brasiliano Cycle.

1 - Depto. Geologia, IGEO, UFRJ, Rio de Janeiro, RJ. E-mails: julio@geologia.ufrj.br, pduffles@geologist.com gcmatos@hotmail.com, ludka@geologia.ufrj.br, fffmedeiros@yahoo.com.br

2 - Depto. de Recursos Minerais RJ, DRM RJ, Niterói, RJ

3 - Depto. de Geologia e Paleontologia, Museu Nacional, UFRJ, Rio de Janeiro, RJ. E-mail: avila@mn.ufrj.br

4 - Pesquisadores do CNPq 
INTRODUÇÃO Entre os municípios de Bom Jardim e Trajano de Moraes (distritos de Barra Alegre e Doutor Elias), região serrana do Estado do Rio de Janeiro, afloram continuamente rochas granitóides porfiríticas numa área de exposição com cerca de $70 \mathrm{~km}^{2}$. Estas rochas não foram individualizadas nos mapas geológicos mais recentes do Estado do Rio de Janeiro (Fonseca 1998, Silva et al. 2000) e são aqui denominadas de Granitóide Barra Alegre. Este trabalho apresenta a integração de dados de campo, petrografia, geoquímica e geocronologia das rochas do corpo granitóide em questão e os interpreta dentro do contexto geotectônico do Segmento Central da Faixa Ribeira.

Trabalhos recentes têm dado ênfase ao estudo de granitóides porfiríticos deformados nesta porção da Faixa Ribeira, onde se tem constatado similaridades geoquímicas e na idade dos corpos estudados (Pereira et al. 2001a, 2001b, Mendes et al. 2006). Os autores apregoam que as idades obtidas, correlacionáveis ao evento sin-colisional Ribeira, devem corresponder a um importante período de geração de magma crustal que resultou em litotipos porfiríticos do tipo I. Neste cenário, o estudo do granitóide Barra Alegre representa efetiva contribuição ao entendimento destes corpos porfiríticos e de seu significado geotectônico na porção crustal considerada.

CONTEXTO GEOLÓGICO REGIONAL A Faixa Neoproterozóica Ribeira se estende por aproximadamente $1.400 \mathrm{~km}$ ao longo da costa sudeste do Brasil e faz parte de uma série de faixas móveis neoproterozóicas / eopaleozóicas geradas pelo amalgamento do supercontinente Gondwana durante o episódio orogênico Brasiliano/Panafricano. Dados geocronológicos apontam que tal atividade orogênica foi diacrônica em sua evolução e se estendeu de $790 \mathrm{Ma}$ a $480 \mathrm{Ma}$ (Heilbron \& Machado 2003). Os principais episódios orogênicos reportados para o Segmento Central da Faixa Ribeira são: a) 790 a $600 \mathrm{Ma}$ - subducção e geração de arco magmático; b) 600 a $560 \mathrm{Ma}$ - episódio colisional I; c) 530 a $510 \mathrm{Ma}$ - episódio colisional II; d) 510 a $480 \mathrm{Ma}$ - colapso orogênico (Machado et al. 1996, Trouw et al. 2000, Campos Neto 2000, Heilbron \& Machado 2003, Schmitt et al. 2004).

Heilbron \& Machado (2003) subdividiram o Segmento Central da Faixa Ribeira nas seguintes unidades tectônicas: terrenos Ocidental, Oriental e Cabo Frio; e Klippe Paraíba do Sul. O Terreno Ocidental compreende um domínio autóctone considerado como margem retrabalhada do Cráton São Francisco e dois sistemas de empurrão com vergência para noroeste, representados pelos domínios Andrelândia e Juiz de Fora, os quais são separados por zonas de cisalhamento. O Terreno Oriental pode ser subdividido em três segmentos: domínios Cambuci e Costeiro e Klippe Italva.

A região serrana do Estado do Rio de Janeiro está inserida no Domínio Costeiro, Terreno Oriental do Segmento Central da Faixa Ribeira, sendo constituída principalmente por: ortognaisses e migmatitos do Complexo Rio Negro, associados aos ortognaisses grano- dioríticos do Batólito Serra dos Órgãos; leucognaisses e rochas metassedimentares do Grupo Paraíba do Sul; e rochas ígneas de composição granodiorítica a granítica, mais raramente gabróica, que intrudem estas unidades (Junho 1993, Mendes et al. 2004).

\section{O GRANITÓIDE BARRA ALEGRE}

Aspectos Geológicos e Estruturais O maciço rochoso é constituído por rochas porfiríticas de composição quartzo-monzonítica a monzogranítica, que geomorfologicamente originam morros do tipo "pão de açucar", dando lugar a uma topografia bastante acidentada (Duffles-Teixeira 2005). Dispõe-se com forma alongada segundo NE-SW, mostrando em mapa contatos que tendem a ser concordantes com a foliação principal das rochas encaixantes (Fig. 1). Estas últimas são representadas por: i) hornblenda-biotita ortognaisse granodiorítico, localmente migmatítico (sobretudo com estrutura estromática), constituinte do arco magmático Rio Negro (Tupinambá 1999); ii) sillimanita-granadabiotita paragnaisse migmatítico, com lentes de rochas calciossilicáticas e, possivelmente, pertencente à Unidade Imbé (Pinto 1980).

O levantamento geológico de campo no Granitóide Barra Alegre permitiu a identificação de duas litofácies: a Fácies Barra Alegre e a Fácies Carijó. A Fácies Barra Alegre predomina amplamente sobre a Fácies Carijó nos afloramentos estudados. Em função da distribuição restrita e heterogênea da fácies Carijó, no mapa geológico (Fig. 1) não foi possível separar as duas litofácies, estando elas genericamente denominadas Granitóide Barra Alegre.

Os litotipos agrupados na Fácies Barra Alegre apresentam granulometria média a grossa, textura porfirítica e estruturas como foliação magmática, lineação mineral de fluxo e fluxo irregular, além de xistosidade incipiente. A variação da proporção matriz/fenocristais localmente pode estar associada à recristalização de fenocristais causada pela deformação. Os fenocristais são de feldspato potássico euédricos a subédricos com até $5 \mathrm{~cm}$ de eixo maior que por vezes apresentam-se amendoados. Esses megacristais geralmente mostram uma orientação preferencial (Fig. 2a), que configura estrutura de fluxo, mas localmente encontram-se irregularmente distribuídos (Fig. 2b). Aglomerações de megacristais são raramente observadas. Tais feições são dependentes da relação entre a intensidade do fluxo ígneo e a proporção de megacristais existentes, deduzindo-se que só localmente houve condições favoráveis para concentração dos mesmos. Outra hipótese seria admitir que representem fase cumulática gerada durante a cristalização da rocha.

A fácies Carijó tem ocorrência restrita na área, particularmente na zona de borda do corpo mapeado, e foi definida a partir de deformação mais intensa sofrida pela fácies Barra Alegre. Assim, trata-se de litotipo que apresenta fenocristais milimétricos de K-feldspato de tendência arredondada a amendoada, localmente oftálmicos (Fig. 2c). A matriz difere daquela presente na fácies Barra Alegre por apresentar maiores evidências de 


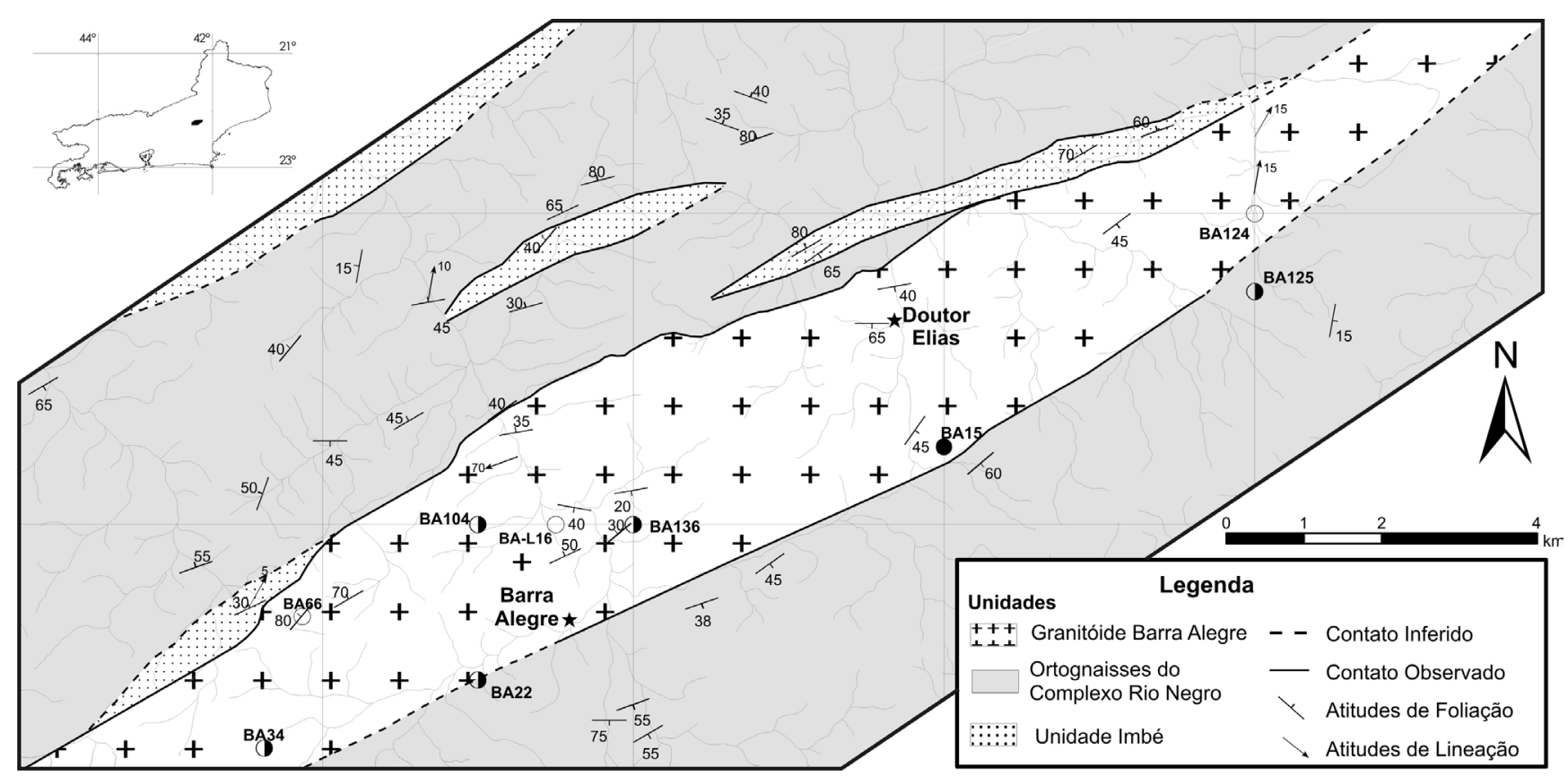

Figura 1 - Mapa Geológico do Granitóide Barra Alegre. Símbolos: círculo vazio - amostras com análise química sem ETR; semi-círculo - amostras com análise química com ETR; círculo cheio: análise geocronológica.

recristalização, com nítida redução da granulometria As rochas desta fácies apresentam xistosidade bem desenvolvida e lineação incipiente. Localmente, a rocha possui aspecto proto-milonítico, exibindo xistosidade muito bem definida.

São observados no Granitóide Barra Alegre, em ambas as litofácies, enclaves xenolíticos de rochas gnáissicas, geralmente alongados paralelamente à foliação e não maiores do que $50 \mathrm{~cm}$ de comprimento, e enclaves máficos, que foram separados em dois tipos. Um deles trata-se de rocha granular mesocrática quartzo-diorítica, rica em anfibólio e biotita. Suas ocorrências são restritas, mas pontualmente aparece em maiores extensões, com formas tabulares métricas, paralelas à orientação da rocha envolvente. $\mathrm{O}$ outro tipo se refere a enclaves estirados de granada-biotita tonalito equigranular, com forte recristalização de quartzo e plagioclásio. Acompanham a foliação geral e ocorrem com maior freqüência nas zonas de borda, sendo, portanto, comumente intercalados com a fácies Carijó. A ocorrência de granada em quantidade considerável nesses últimos enclaves, aliada à sua predominância nas bordas do maciço, sugere que eles sejam porções máficas ou melanossomas de rocha gnáissica encaixante.

A distribuição do strain no corpo é heterogênea em escala regional e se manifesta através de estruturas como: bandamento composicional (intercalação entre fácies Carijó e enclaves), xistosidade contínua definida por agregados máficos (biotita), e lineações de objeto (Passchier \& Trouw 2005) pouco desenvolvidas, definidas por agregados prolatos de quartzo e quartzofeldspáticos. As tramas planares e lineares podem ser agrupadas em dois grupos (Passchier \& Trouw, 2005, Paterson et al., 1989): a) tramas primárias de natureza magmática; b) tramas secundárias desenvolvidas em estado sólido, resultado de deformação acompanhada de recristalização. As tramas de caráter secundário estão concentradas sobretudo nas zonas de borda, onde predominam os litotipos da Fácies Carijó, sendo que as de origem magmática estão amplamente distribuídas na Fácies Barra Alegre. Nota-se claramente a obliqüidade $\left(<45^{\circ}\right)$ entre as orientações primárias dos fenocristais, sejam elas planares ou lineares, e a xistosidade (foliação secundária), que pode localmente imprimir geometria 'S-C' nos litotipos de domínios com maior intensidade de strain finito. Este fato indica provável superimposição de estruturas geradas por fluxo dúctil (sub-solidus) sobre estruturas geradas por fluxo magmático (Paterson et al. 1989).

Os mergulhos da xistosidade nas zonas de borda sugerem a existência de estrutura antiformal, orientado NE-SW e paralelo à estruturação regional do Segmento Central da Faixa Ribeira. A xistosidade nos litotipos Granitóide Barra Alegre encontra-se subparalela à foliação metamórfica principal dos gnaisses encaixantes, demonstrando que a superimposição da deformação sobre o corpo foi tardia ao episódio colisional I do Segmento Central da Faixa Ribeira (Heilbron \& Machado 2003). Veios félsicos com dobras suaves a abertas também ocorrem, mas não demonstram relação nítida com as foliações observadas no corpo e nas unidades encaixantes. Pontualmente, pequenos dobramentos caracterizam foliação plano axial.

A orientação das lineações de objeto primárias (mineral) e secundárias (de agregados), também segue a tendência de estruturação regional com caimentos para NE e SW. O fato de a lineação de fluxo magmático estar aproximadamente concordante com a lineação de estiramento corrobora com o a hipótese de que, mesmo durante o estágio magmático, o corpo estava condicio- 


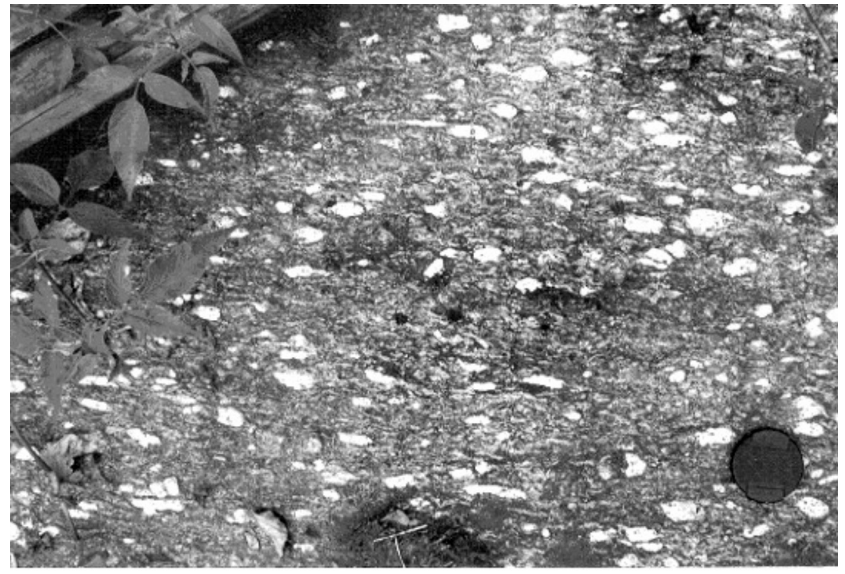

a

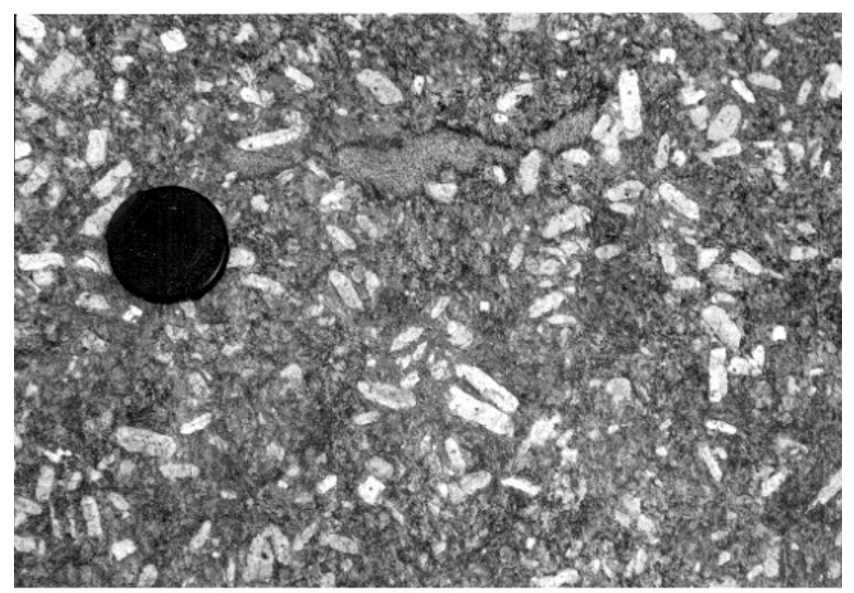

b

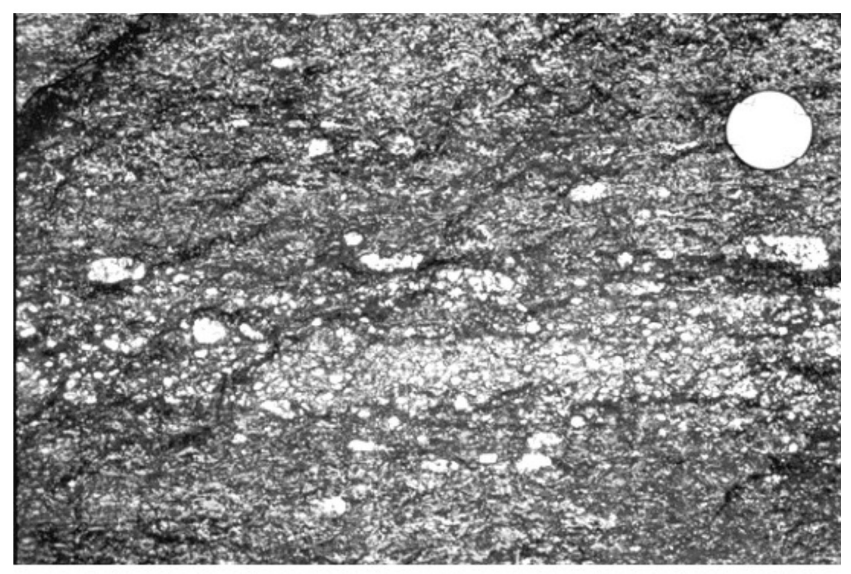

c

Figura 2 - (a) Orientação preferencial de megacristais de K-feldspato da litofácies Barra Alegre; (b) Arranjo irregular de megacristais de K-feldspato na litofácies Barra Alegre; (c) Detalhe da litofácies Carijó, onde se observam fenocristais de K-feldspato com aspecto arredondado a amendoado.

nado a um campo de tensões com orientação principal NE-SW.

Petrografia Ao microscópio, a fácies Barra Alegre é caracterizada por mostrar megacristais de microclina e matriz fina/média inequigranular hipidiomórfica de composição granodiorítica a tonalítica. Quartzo, plagioclásio $\left(\mathrm{An}_{28}\right)$, biotita e microclina são as fases essenciais e minerais opacos (magnetita, ilmenita e pirita), zircão, apatita, hornblenda, allanita e titanita aparecem como minerais acessórios. Muscovita/sericita, calcita e clorita são minerais secundários.

Os grãos de quartzo mostram muitas vezes extinção ondulante e lamelas de deformação. Seus contatos são irregulares a interlobados, por vezes invadindo fases essenciais como os feldspatos. Cristais de plagioclásio contêm freqüentes inclusões de zircão, apatita e minerais opacos e mostram feições de recristalização como extinção ondulante e lamelas de geminação acunhadas ou recurvadas. Localmente ocorrem agregados quartzo-feldspáticos com forma poligonizada e distribuição seriada da granulometria, que varia de muito fina a fina. As lamelas de biotita apresentam contatos serrilhados e dobras suaves e por vezes estão em junção tríplice com grãos de quartzo e plagioclásio. Kosaka et al. (1999) apontam que tais efeitos de deformação em grãos de quartzo, plagioclásio e biotita podem ser gerados tanto a partir de esforços no estado sólido, como durante a cristalização de líquidos graníticos, quando o magma se comporta como mush. A microclina mostra típica geminação "tartan", com poucas lamelas pertíticas, estando eventualmente bastante sericitizada e caulinizada. Tanto os fenocristais quanto os grãos da matriz podem apresentar novos grãos em seus entornos e extinção ondulante. Nos litotipos da fácies Barra Alegre atuaram mecanismos de recristalização dinâmica acompanhados de recristalização estática, tais como os descritos por Passchier \& Trouw (2005). Os limites dos grãos de feldspato apresentam irregularidades que podem ser interpretadas como produto de recristalização por migração dos limites dos grãos ou, localmente, por rotação de subgrãos nas bordas dos grãos de K-feldspato.

A fácies Carijó possui composição mineralógica similar, exceto pela presença de granada, identificada em uma única amostra. Os fenocristais de microclina têm tamanhos reduzidos (em geral não ultrapassam 1 $\mathrm{cm}$ ) e as feições de deformação, bem menos freqüentes na fácies Barra Alegre, são peculiares e facilmente perceptíveis: microclina intensamente recristalizada formando um manto de novos grãos ao redor dos fenocristais; grãos de quartzo muito deformados, com extinção ondulante, gerando subgrãos e formando fitas que marcam a orientação da rocha; lamelas de biotita e grãos de microclina lenticulares. Via de regra, agregados de quartzo e microclina apresentam formas alongadas que caracterizam lineações de estiramento descritas em escala mesoscópica. Na matriz granítica da fácies Carijó, bastante recristalizada, a porcentagem de microclina é muito superior à encontrada na matriz das amostras da fácies Barra Alegre.

A classificação petrográfica das rochas estudadas foi feita com base em sua distribuição no diagrama QAP (Fig. 3), que traz amostras de ambas litofácies do Granitóide Barra Alegre e de três enclaves máficos. 


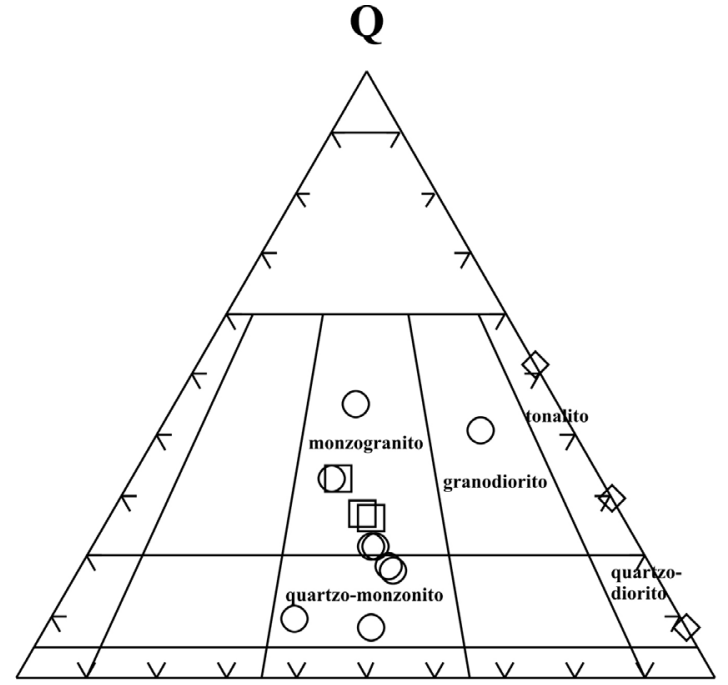

A

Figura 3 - Diagrama de classificação modal QAP para o granitóide Barra Alegre e enclaves relacionados. Símbolos: O: Litofácies Barra Alegre; $\square$ : Litofácies Carijó; ৩: Enclaves máficos

Para a obtenção das proporções modais de K-feldspato foi feita uma interpolação entre as porcentagens de fenocristais da rocha $(30 \%$ em média, obtida por contagens em afloramento) com as proporções de microclina da matriz, obtidas por contagem modal ao microscópio (Duffles-Teixeira 2005). Foram contados 800 pontos para a obtenção das porcentagens modais e nas variedades megaporfiríticas foram contados apenas os minerais da matriz. A composição modal das amostras estudadas (matriz mais fenocristais) está apresentada na tabela 1. Dentre os granitóides, observa-se uma tendência evolutiva de quartzomonzonito a monzogranito, com apenas uma amostra (BA-34) situando-se no campo dos granodioritos.

\section{GEOQUÍMICA}

Métodos Analíticos Elementos maiores e traços foram dosados no Laboratório de Fluorescência de raios $X$ do Departamento de Geologia, Universidade Federal do Rio de Janeiro, através de espectrômetro de fluorescência de raios X Philips PW2400, com tubo de Rh. A perda ao fogo foi obtida através da obtenção do peso da amostra antes e depois da mesma ser aquecida a $950^{\circ} \mathrm{C}$ por meia hora. Os elementos maiores foram detectados a partir da fusão de $1,2 \mathrm{~g}$ de pó do material com tetraborato de lítio. Os elementos traços foram determinados em $7 \mathrm{~g}$ do pó da amostra, prensada com $1 \mathrm{~g}$ de aglutinante wax. Os elementos leves foram dosados com as seguintes condições: detetor de fluxo, cristal analisador PET/Ge e potência do tubo $40 \mathrm{kV}-70 \mathrm{~mA}$. Os elementos pesados foram analisados com detetor selado, cristais analisadores LIF200/LIF220 e potência do tubo $50 \mathrm{kV}-50 \mathrm{~mA}$. Com base em análises de padrões, o erro analítico relativo estimado foi: $\mathrm{Si}, \mathrm{Al}(<1 \%), \mathrm{Fe}$, $\mathrm{Mg}, \mathrm{Ca}(1-2 \%)$, Ti, Na, K (3-5\%), P e outros elementos traços $(\leq 6 \%)$. As curvas de calibração foram obtidas a partir da análise dos seguintes padrões internacionais: NIM-P, 521-84n, GBW07112, GIT-IWG, ANRT, BE-N GIT, PM-S GIT, CRPG BR, AN-G GIT, GBW07104, GBW07110, GBW07111, AC-E, GS-N, MA-N, CRPG $\mathrm{GH}$. Elementos terras raras foram analisados no laboratório Acme Analytical Laboratories Ltd. (Vancouver, Canadá) por meio de equipamento ICP-MS, a partir da fusão de $0,5 \mathrm{~g}$ de amostra com $\mathrm{LiBO}_{2}$.

Dados Litogeoquímicos Foram realizadas nove análises químicas de elementos maiores e traços (sendo seis análises para elementos terras raras), todos da fácies Barra Alegre, pois não foram obtidas amostras adequadas de rochas da fácies Carijó, em função da sua distribuição restrita e da alteração apresentada.

A tabela 2 apresenta os resultados obtidos das análises químicas de elementos maiores e traços, incluindo os elementos terras raras. Para a normalização de ETR foi utilizado o condrito de Boynton (1984). As amostras analisadas apresentam teores de $\mathrm{SiO}_{2}$ entre $63,7 \%$ e $68,0 \%$ em peso, o que as posiciona no intervalo proposto por Le Maitre (1989) e Nockolds \& Allen (1954) para rochas granodioríticas. Ao se comparar com o banco de dados destes autores constata-se que o magmatismo estudado é enriquecido em Fe, K, Ti e P e ligeiramente empobrecido em Na. A variação dos teores de $\mathrm{SiO}_{2}$ o caracteriza como um tipo moderadamente diferenciado e evoluído, formando uma seqüência pouco expandida de caráter ácida.

Utilizando-se o diagrama $\left(\mathrm{Na}_{2} \mathrm{O}+\mathrm{K}_{2} \mathrm{O}\right) \times \mathrm{SiO}_{2}$ de Cox et al. (1979), adaptado por Wilson (1991), e o diagrama QxP de Debon \& Le Fort (1983) para classificação de rochas plutônicas, as amostras do granitóide Barra Alegre situam-se preferencialmente nos campos do granodiorito (Figs. 4 e 5). Desta maneira, caracterizou-se uma discrepância entre a classificação modal (quartzomonzonitos e monzogranitos) e química (granodioritos) das rochas do Granitóide Barra Alegre. A mesma deve estar associada à problemática que envolve a classificação de litotipos inequigranulares megaporfiríticos, pois tanto uma classificação modal de boa precisão quanto a homogeneização, para análise química, deste tipo de rocha é muito difícil. Esta variação na designação pode também estar relacionada ao fato que os autores dos diagramas geoquímicos supracitados utilizaram análises químicas de rochas sem grandes variações granulométricas para a delimitação dos campos composicionais.

Na diagrama AFM da figura 6, as amostras do Granitóide Barra Alegre posicionam-se no campo proposto por Irvine \& Baragar (1971) para as composições cálcio-alcalinas. Frost et al. (2001) elaboraram uma classificação química de granitóides baseada na concentração de alguns elementos maiores, sem considerar aspectos genéticos e de ambiente tectônico da evolução dos mesmos. Fazendo-se uso dos critérios definidos por eles, as rochas aqui estudadas seriam consideradas magnesianas (em função de seus moderados $\mathrm{Fe} \#$ ) e cálcicas a cálcio-alcalinas (segundo o índice de 
Tabela 1 - Contagem modal (\% em vol.) de amostras do Granitóide Barra Alegre e enclaves máficos.

\begin{tabular}{|c|c|c|c|c|c|c|c|c|c|c|c|c|c|c|c|}
\hline & $\begin{array}{c}\text { BA-L- } \\
19^{* *}\end{array}$ & $\begin{array}{l}\text { BA - } \\
8^{* * * *}\end{array}$ & $\begin{array}{l}\text { BA- } \\
15^{*}\end{array}$ & $\begin{array}{l}\text { BA8 } \\
102 \\
* * *\end{array}$ & $\begin{array}{l}\text { BA- } \\
34 *\end{array}$ & $\begin{array}{l}\text { BA- } \\
66^{*}\end{array}$ & $\begin{array}{c}\text { BA- } \\
83^{* * *}\end{array}$ & $\begin{array}{l}\text { BA- } \\
104^{*}\end{array}$ & $\begin{array}{c}\text { BA- } \\
121^{* *}\end{array}$ & $\begin{array}{l}\text { BA- } \\
123^{* *}\end{array}$ & $\begin{array}{l}\text { BA- } \\
125^{*}\end{array}$ & $\begin{array}{l}\text { BA- } \\
124 *\end{array}$ & $\begin{array}{c}\text { BA-L- } \\
16^{*}\end{array}$ & $\begin{array}{l}\text { BA- } \\
136^{*}\end{array}$ & $\begin{array}{l}\text { BA- } \\
22^{*}\end{array}$ \\
\hline Quartzo & 28,8 & 22,7 & 36,8 & 40,0 & 32,1 & 19,0 & 4,0 & 25,9 & 22,0 & 22,2 & 14,1 & 14,6 & 6,8 & 7,7 & 17,6 \\
\hline Plagioclásio & 25,9 & 53,4 & 20,6 & 37,5 & 36,3 & 35,2 & 45,7 & 22,9 & 31,6 & 29,5 & 36,5 & 35,5 & 38,5 & 27,7 & 33,3 \\
\hline Biotita & 12,1 & 21,9 & 18,2 & 20,5 & 20,0 & 10,9 & 37,3 & 18,3 & 15,5 & 17,1 & 19,2 & 18,1 & 17,2 & 19,3 & 17,5 \\
\hline K-feldspato & 32,7 & --- & 23,5 & --- & 10,2 & 33,8 & --- & 30,4 & 30,3 & 30,1 & 30,1 & 30,1 & 37,1 & 44,0 & 30,9 \\
\hline Opacos & $\operatorname{tr}$ & 0,3 & 0,4 & $\operatorname{tr}$ & 0,2 & $\operatorname{tr}$ & 1,0 & 0,4 & $\operatorname{tr}$ & 0,3 & $\operatorname{tr}$ & 0,2 & 0,2 & 0,2 & $\operatorname{tr}$ \\
\hline Zircão & $\operatorname{tr}$ & $\operatorname{tr}$ & $\operatorname{tr}$ & $\operatorname{tr}$ & $\operatorname{tr}$ & $\operatorname{tr}$ & $\operatorname{tr}$ & $\operatorname{tr}$ & $\operatorname{tr}$ & $\operatorname{tr}$ & 0,1 & $\operatorname{tr}$ & $\operatorname{tr}$ & $\operatorname{tr}$ & 0,2 \\
\hline Apatita & $\operatorname{tr}$ & $\operatorname{tr}$ & $\operatorname{tr}$ & $\operatorname{tr}$ & $\operatorname{tr}$ & $\operatorname{tr}$ & $\operatorname{tr}$ & $\operatorname{tr}$ & $\operatorname{tr}$ & $\operatorname{tr}$ & $\operatorname{tr}$ & $\operatorname{tr}$ & $\operatorname{tr}$ & $\operatorname{tr}$ & $\operatorname{tr}$ \\
\hline Hornblenda & --- & --- & $\operatorname{tr}$ & $\begin{array}{l}-- \\
---\end{array}$ & --- & --- & 12,0 & --- & $\begin{array}{l}-- \\
---\end{array}$ & 0,8 & --- & --- & --- & --- & --- \\
\hline Allanita & --- & --- & $\operatorname{tr}$ & --- & $\operatorname{tr}$ & --- & $\operatorname{tr}$ & --- & --- & $\operatorname{tr}$ & $\operatorname{tr}$ & --- & --- & $\operatorname{tr}$ & 0,1 \\
\hline Titanita & --- & --- & $\operatorname{tr}$ & --- & $\operatorname{tr}$ & --- & --- & $\operatorname{tr}$ & --- & $\operatorname{tr}$ & $\operatorname{tr}$ & --- & --- & $\operatorname{tr}$ & $\operatorname{tr}$ \\
\hline Secundários & 0,5 & 0,3 & 0,5 & 2,0 & 1,2 & 1,1 & --- & 2,1 & 0,6 & --- & --- & 1,5 & 0,2 & 1,1 & 0,4 \\
\hline Granada & --- & 1,4 & --- & --- & --- & --- & --- & --- & --- & --- & --- & --- & --- & --- & --- \\
\hline Total & 100,0 & 100,0 & 100,0 & 100,0 & 100,0 & 100,0 & 100,0 & 100,0 & 100,0 & 100,0 & 100,0 & 100,0 & 100,0 & 100,0 & 100,0 \\
\hline
\end{tabular}

\begin{tabular}{l|c|c|c|c|c|c|c|c|c|c|c|c|c|c|c}
\hline $\mathrm{Q}$ & 32,9 & 29,7 & 45,0 & 51,6 & 40,8 & 21,6 & 8,1 & 32,7 & 26,3 & 27,1 & 17,5 & 18,2 & 8,3 & 9,7 & 21,5 \\
\hline $\mathrm{A}$ & 37,4 & --- & 29,0 & --- & 13,0 & 38,4 & --- & 38,4 & 36,0 & 36,8 & 37,3 & 37,5 & 45,0 & 55,4 & 37,8 \\
\hline $\mathrm{P}$ & 29,7 & 70,3 & 26,0 & 48,4 & 46,2 & 40,0 & 91,9 & 28,9 & 37,7 & 36,1 & 45,2 & 44,3 & 46,7 & 34,9 & 40,7 \\
\hline
\end{tabular}

*ácies Barra Alegre; **fácies Carijó; ***enclave máfico

$\operatorname{tr}=$ traços; Secundários: muscovita/sericita, calcita e clorita

Peacock modificado pelos autores). Utilizando-se o diagrama $\mathrm{SiO}_{2}$ x $\mathrm{K}_{2} \mathrm{O}$ de Peccerillo \& Taylor (1976), observa-se que as amostras do Granitóide Barra Alegre se posicionam preferencialmente no campo referente a litotipos de alto K (Fig. 7), o que permite inferir que se trata de magmatismo cálcio-alcalino de alto K. Com relação ao índice de saturação de alumínio (ASI), Frost et al. (2001) propuseram que ele seja calculado considerando-se também a proporção molar de $\mathrm{P}$ (presença de apatita), além de $\mathrm{Al}, \mathrm{Ca}, \mathrm{Na}$ e $\mathrm{K}$, conforme definição clássica de Shand (1943). Desta maneira, as amostras do Granitóide Barra Alegre apresentam valo-

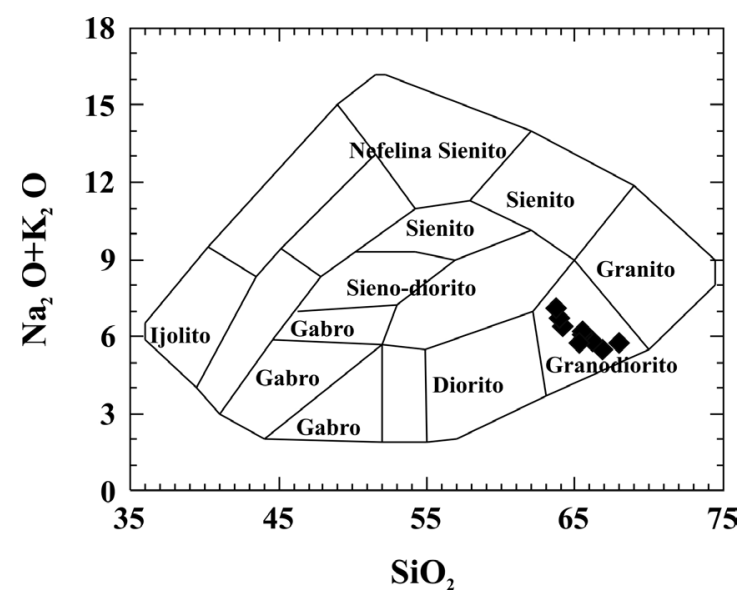

Figura 4-Diagrama de classificação geoquimica $\mathrm{SiO}_{2} \times \mathrm{K}_{2} \mathrm{O}+\mathrm{Na}_{2} \mathrm{O}$ (Cox et al. 1979) para o Granitóide Barra Alegre. res de ASI ligeiramente superiores a 1,0, atestando um caráter fracamente peraluminoso. Ao serem consideradas as razões A/CNK (Tab. 2), que se situam entre 1,0 e 1,1, o resultado obtido é o mesmo e a figura 8 ilustra tal característica. Clarke (1981) chama a atenção para o fato de que em direção aos termos mais evoluídos de seqüências ácidas tipo I existe uma forte tendência à cristalização de rochas levemente peraluminosas. Frost et al. (2001) salientam que nas rochas fracamente peraluminosas o excesso em alumínio pode estar alocado na biotita, que é a principal fase máfica do Granitóide Barra Alegre.

Os diagramas de Harker (Fig. 9) evidenciam que alguns elementos maiores e traços não definem trends. Uma possível explicação seria que as composições químicas de amostras com megacristais podem não representar as composições de líquidos e por isto podem não formar um liquid line of descent, resultando muitas vezes num maior espalhamento das amostras analisadas (Cox et al. 1979). Entretanto, observa-se uma tendência ao decréscimo dos teores de $\mathrm{TiO}_{2}, \mathrm{Al}_{2} \mathrm{O}_{3}$, $\mathrm{Fe}_{2} \mathrm{O}_{3}, \mathrm{CaO}, \mathrm{Na}_{2} \mathrm{O}, \mathrm{K} 2 \mathrm{O}, \mathrm{Rb}$ e $\mathrm{Sr}$ com o aumento do teor de $\mathrm{SiO}_{2}$. O comportamento do Ca difere dos outros elementos ao conferir maior dispersão dos pontos analisados, mas algumas amostras possuem concentrações próximas a 3,8\% $\mathrm{CaO}$, sugerindo a existência de dois grupos distintos.

A correlação negativa de $\mathrm{Al}_{2} \mathrm{O}_{3}$ pode estar relacionada com uma cristalização precoce e possivelmente simultânea de fenocristais de K-feldspato e plagioclásio, este cada vez mais pobre em $\mathrm{Ca}$. Tal fato é reafirmado ao se observar a tendência na diminuição de 
Tabela 2 - Resultados de análises químicas de elementos maiores (\% em peso) e traços (em ppm) e parâmetros geoquímicos para amostras do Granitóide Barra Alegre.

\begin{tabular}{l|c|c|c|c|c|c|c|c|c}
\hline & BA-34 & BA-15 & $\begin{array}{c}\text { BA- } \\
125\end{array}$ & $\begin{array}{c}\text { BA-L- } \\
16\end{array}$ & BA-22 & $\begin{array}{c}\text { BA- } \\
136\end{array}$ & $\begin{array}{c}\text { BA- } \\
124\end{array}$ & $\begin{array}{c}\text { BA- } \\
104\end{array}$ & BA-66 \\
\hline $\mathrm{SiO}_{2}$ & 63,68 & 63,97 & 64,20 & 65,30 & 65,52 & 65,56 & 66,16 & 66,80 & 68,00 \\
\hline $\mathrm{TiO}_{2}$ & 0,97 & 0,89 & 0,88 & 0,87 & 0,82 & 0,82 & 0,87 & 0,95 & 0,77 \\
\hline $\mathrm{Al}_{2} \mathrm{O}_{3}$ & 16,78 & 15,55 & 15,78 & 15,25 & 15,82 & 15,45 & 14,92 & 15,12 & 14,54 \\
\hline $\mathrm{Fe}_{2} \mathrm{O}_{3 \mathrm{~T}}$ & 5,69 & 5,15 & 5,17 & 5,31 & 4,94 & 4,92 & 5,11 & 5,49 & 4,34 \\
\hline $\mathrm{MnO}$ & 0,07 & 0,07 & 0,07 & 0,07 & 0,06 & 0,06 & 0,05 & 0,07 & 0,05 \\
\hline $\mathrm{MgO}$ & 2,06 & 1,89 & 1,98 & 2,05 & 1,84 & 1,81 & 1,92 & 2,16 & 1,56 \\
\hline $\mathrm{CaO}$ & 3,45 & 3,94 & 3,71 & 3,82 & 3,76 & 3,45 & 3,37 & 3,78 & 3,22 \\
\hline $\mathrm{Na} 2 \mathrm{O}$ & 3,44 & 3,26 & 2,9 & 3,00 & 3,06 & 2,82 & 2,8 & 2,74 & 2,56 \\
\hline $\mathrm{K}_{2} \mathrm{O}$ & 3,64 & 3,45 & 3,51 & 2,78 & 3,17 & 3,27 & 3,03 & 2,72 & 3,20 \\
\hline $\mathrm{P}_{2} \mathrm{O}_{5}$ & 0,45 & 0,22 & 0,23 & 0,23 & 0,2 & 0,23 & 0,21 & 0,22 & 0,16 \\
\hline $\mathrm{P.F}$. & 0,70 & 0,70 & 0,80 & 1,20 & 0,70 & 1,20 & 0,80 & 0,50 & 0,80 \\
\hline Total & 100,93 & 99,09 & 99,23 & 99,88 & 99,89 & 99,59 & 99,24 & 100,55 & 99,20 \\
\hline
\end{tabular}

\begin{tabular}{l|c|c|c|c|c|c|c|c|c}
\hline $\mathrm{Cr}$ & 26 & 31 & 22 & 28 & 40 & 20 & 23 & 32 & 13 \\
\hline $\mathrm{Ni}$ & 5 & 14 & 10 & 44 & 14 & 7 & 13 & 11 & 8 \\
\hline $\mathrm{V}$ & 102 & 80 & 89 & 68 & 86 & 81 & 93 & 89 & 67 \\
\hline $\mathrm{Zn}$ & 56 & 50 & 38 & 34 & 60 & 39 & 39 & 41 & 35 \\
\hline $\mathrm{Rb}$ & 144 & 94 & 92 & 96 & 104 & 110 & 99 & 94 & 90 \\
\hline $\mathrm{Ba}$ & 894 & 1015 & 1205 & 935 & 957 & 859 & 909 & 937 & 1106 \\
\hline $\mathrm{Sr}$ & 391 & 317 & 294 & 282 & 294 & 247 & 257 & 257 & 273 \\
\hline $\mathrm{Ga}$ & 19 & 18 & 15 & 13 & 18 & 15 & 16 & 16 & 15 \\
\hline $\mathrm{Nb}$ & 18 & 15 & 14 & 8,0 & 16 & 16 & 16 & 15 & 12 \\
\hline $\mathrm{Zr}$ & 227 & 200 & 236 & 160 & 176 & 196 & 247 & 232 & 245 \\
\hline $\mathrm{Y}$ & 36 & 30 & 28 & 14 & 25 & 33 & 27 & 26 & 23 \\
\hline $\mathrm{Th}$ & 1,9 & 8 & 6,6 & N.D & 9,1 & 11,3 & N.D & 2,4 & N.D \\
\hline $\mathrm{U}$ & 2,0 & 0,9 & 0,4 & N.D & 0,8 & 1,0 & N.D & 0,7 & N.D \\
\hline
\end{tabular}

N.D.:

não detectado;

P.F.:

Perda ao fogo;

A/CNK:

$\mathrm{Al}_{2} \mathrm{O}_{3} /\left(\mathrm{N}_{2} \mathrm{O}+\mathrm{CaO}\right.$

$\left.+\mathrm{K}_{2} \mathrm{O}\right)$;

Mg\#:

$(\mathrm{MgO} / 40,3) /$

$\{(\mathrm{MgO} / 40,3)+$

$\left.\left(\mathrm{Fe}_{2} \mathrm{O}_{3} / 159,69\right) * 2\right\}$

$E u / E u * N$ :

$(E u / 0,0735) /$

$\{[(\mathrm{Sm} / 0,195)+$

$(G d / 0,259)] / 2\}$;

Normalização

utilizada:

Boynton, 1984.

\begin{tabular}{|c|c|c|c|c|c|c|}
\hline $\mathrm{Gd}$ & 5,04 & 6,41 & 4,90 & 5,1 & 5,17 & 4,19 \\
\hline $\mathrm{Tb}$ & 0,74 & 0,98 & 0,84 & 0,61 & 0,94 & 0,70 \\
\hline Dy & 3,59 & 5,33 & 3,56 & 3,08 & 4,87 & 3,47 \\
\hline Ho & 0,75 & 1,01 & 0,68 & 0,56 & 0,91 & 0,63 \\
\hline Er & 1,81 & 2,29 & 2,17 & 1,35 & 2,43 & 1,66 \\
\hline $\mathrm{Tm}$ & 0,25 & 0,31 & 0,32 & 0,17 & 0,33 & 0,20 \\
\hline $\mathrm{Yb}$ & 1,46 & 1,61 & 1,61 & 1,01 & 1,84 & 1,12 \\
\hline $\mathrm{Lu}$ & 0,25 & 0,26 & 0,27 & 0,13 & 0,30 & 0,25 \\
\hline Total ETR & 135,85 & 240,66 & 224,25 & 216,41 & 185,96 & 128,21 \\
\hline$(\mathrm{Ce} / \mathrm{Yb}) \mathrm{N}$ & 9.67 & 16,81 & 14,89 & 2420 & 1091 & 1180 \\
\hline$(\mathrm{Dy} / \mathrm{Yb}) \mathrm{N}$ & 1,60 & 2,15 & 1,44 & 1,98 & 1,72 & 2,01 \\
\hline $\mathrm{Eu} / \mathrm{Eu}^{*} \mathrm{~N}$ & 0,75 & 0,74 & 0,89 & 0,83 & 0,84 & 1,01 \\
\hline
\end{tabular}

Boynton, 1984.

teores de $\mathrm{Na}_{2} \mathrm{O}$ e $\mathrm{CaO}$ com o aumento de $\mathrm{SiO}_{2}$. Esperava-se, no entanto, um aumento do teor de $\mathrm{K}_{2} \mathrm{O}$ em relação à sílica. A tendência a uma correlação negativa para este óxido pode ser explicada por se tratar de uma rocha porfirítica rica em fenocristais de feldspato potássico.
Neste contexto, o aporte de K a partir do magma deve ter sido mais ou menos regular durante a cristalização da seqüência, implicando provavelmente na formação precoce de megacristais de microclina, assim como na nucleação e crescimento inicial de biotita. A pequena 


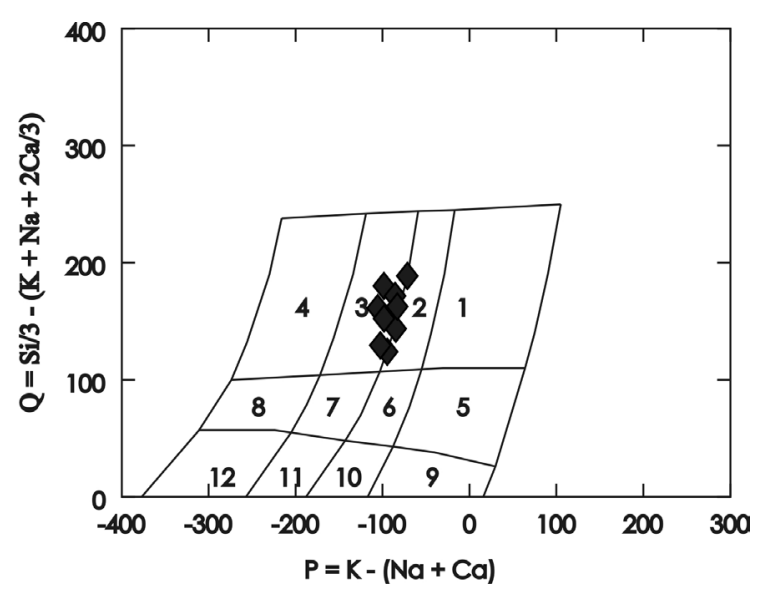

Figura 5 - Diagrama de classificação geoquimica QxP (Debon \& Le Fort 1983) para o Granitóide Barra Alegre. (1) granito, (2) adamelito, (3) granodiorito, (4) tonalito, (5) quartzo-sienito, (6) quartzo-monzonito, (7) quartzo-monzodiorito, (8) quartzo-diorito/gabro, (9) sienito, (10) monzonito, (11) monzogabro, (12) gabro/ diorito.

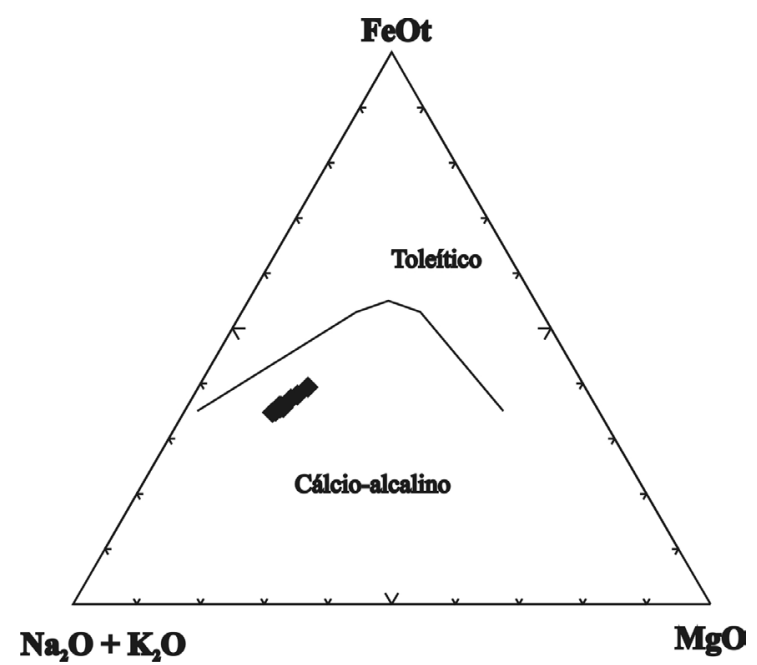

Figura 6 - Diagrama AFM (Irvine \& Baragar 1971) para o Granitóide Barra Alegre.

variação dos teores de $\mathrm{MgO}, \mathrm{P}_{2} \mathrm{O}_{5}$ e $\mathrm{Zr}$ em relação aos teores de $\mathrm{SiO}_{2}$ mostra que a disponibilidade de $\mathrm{MgO}$ para a formaçã̃o de fases máficas, de $\mathrm{P}_{2} \mathrm{O}_{5}$ para a formação de apatita e de $\mathrm{Zr}$ para a formação de zircão, não diferiu muito ao longo da cristalização do magma. A diminuição de $\mathrm{V}$ com o aumento da sílica aponta para o provável e esperado controle dos óxidos de ferro e talvez biotita na distribuição deste elemento, uma vez que em direção aos termos mais evoluídos a proporção modal desses minerais tende a diminuir.

Os totais dos elementos terras raras não são diretamente relacionados com a variação dos teores de $\mathrm{SiO}_{2}$, uma vez que seria esperado um aumento dos valores de $\mathrm{ETR}_{\mathrm{T}}$ com o enriquecimento de sílica (Tab.

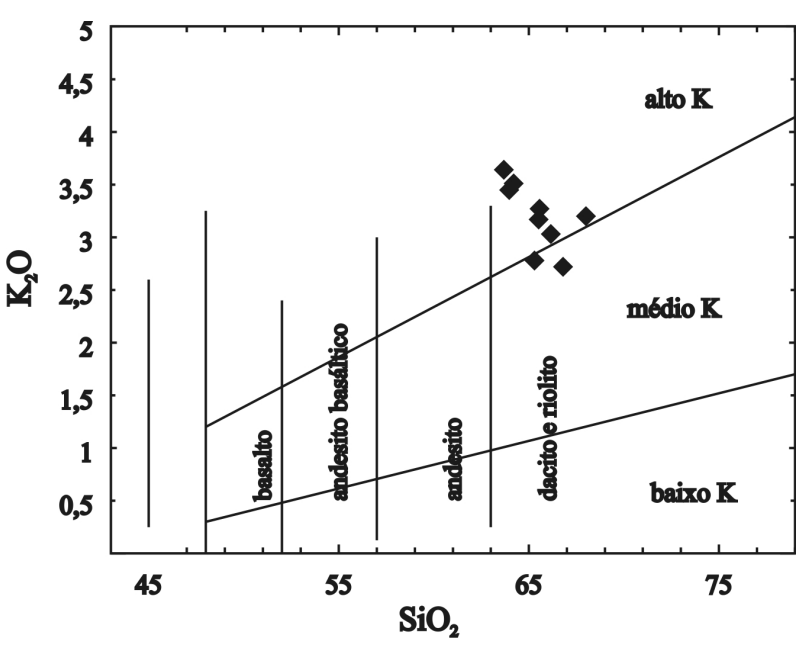

Figura 7 - Diagrama $\mathrm{SiO}_{2} \times \mathrm{K}_{2} \mathrm{O}$ (Peccerillo \& Taylor, 1976) para o Granitóide Barra Alegre.

2). Comparando-se as concentrações de $\mathrm{SiO}_{2}$ com os teores de ETR totais, observamos que a amostra BA-15 apresenta a maior concentração de ETR. No entanto, tal amostra apresenta baixas concentrações de $\mathrm{SiO}_{2}$. Concomitantemente, a amostra BA-104 apresenta a menor concentração de ETR e o maior teor de $\mathrm{SiO}_{2}$ dentre as amostras analisadas. Tal fato pode ser explicado pela cristalização precoce de fases acessórias concentradoras de ETR, tais como allanita, apatita, hornblenda, titanita e zircão, uma vez que a variação de $\mathrm{SiO}_{2}$ da seqüência é pequena. Vale ressaltar que a amostra BA-15 destaca-se pela presença de hornblenda, allanita e titanita, além de grande quantidade de apatita e zircão. Por outro lado, na amostra BA-104 estão ausentes hornblenda e allanita e há menor quantidade de apatita, titanita e zircão.

A figura 10 apresenta o padrão de elementos terras raras, com considerável enriquecimento nos elementos terras raras leves (ETRL), variando de 100 a 200 vezes o condrito, bem como suave anomalia negativa de Eu, sugerindo retenção do elemento na fonte ou fracionamento de plagioclásio durante a cristalização

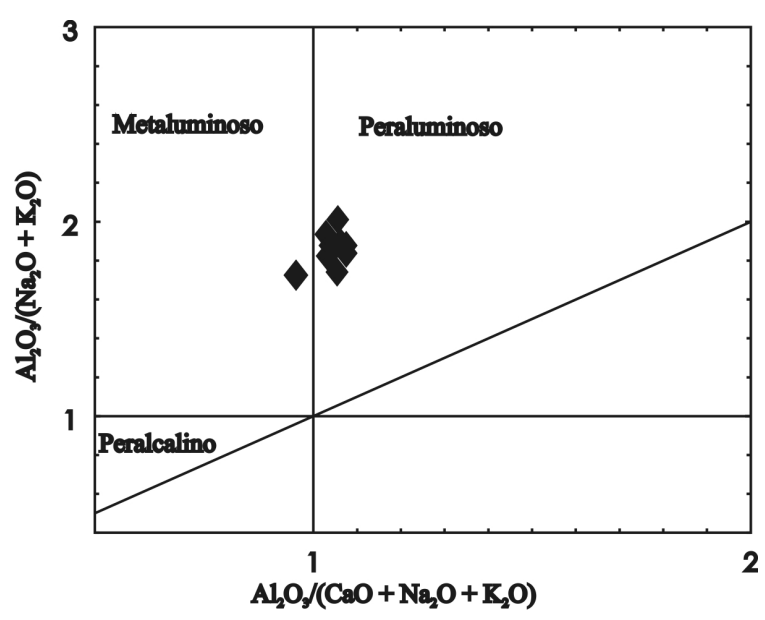

Figura 8 - Diagrama A/CNK $x$ CNK (Shand, 1943) para o Granitóide Barra Alegre. 

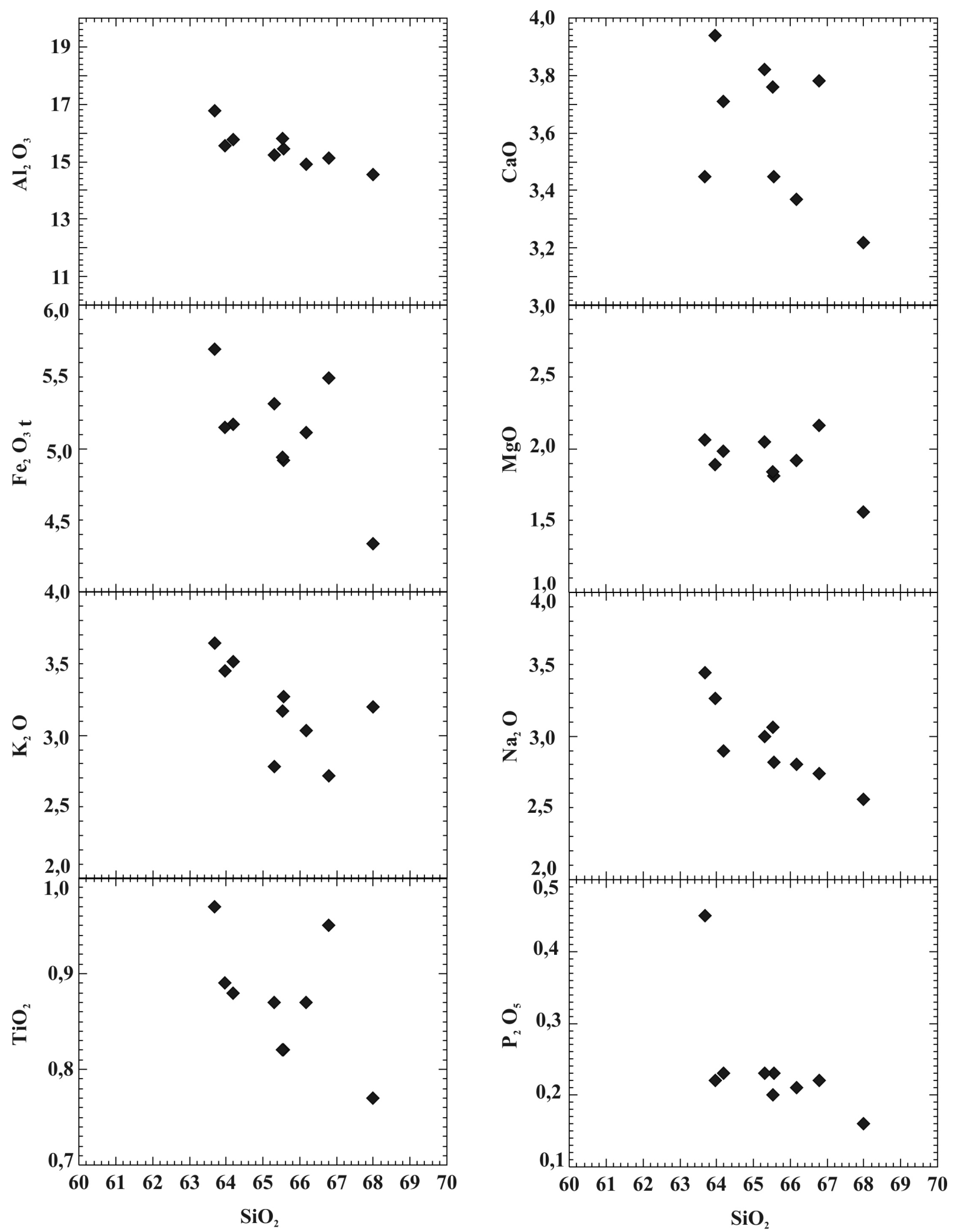

Figura 9 -Diagramas de Harker para o Granitóide Barra Alegre.

do magma. A variação das concentrações de ETR das amostras analisadas resultou em um padrão moderadamente fracionado e relativamente homogêneo, com razões $\mathrm{Ce} / \mathrm{Yb}_{\mathrm{N}}$ variando de 9,67 a 24,20, o que aponta afinidade genética para a seqüência de rochas estudadas.

Utilizando-se os parâmetros idealizados por Chapell \& White (1974) para a classificação geoquí- mica de granitos, tem-se que as amostras do Granitóide Barra Alegre mostram características pertinentes tanto a granitos do tipo I $(\mathrm{A} / \mathrm{CNK}<1,1$; conteúdos moderados de $\mathrm{Na}_{2} \mathrm{O}$ para o intervalo de sílica da seqüência; diagramas de variação quase lineares) quanto a granitos do tipo $\mathrm{S}$ (corindon normativo; composições relativamente restritas para a variação de sílica apresentada). Ao revisitarem os conceitos elaborados, a partir de novos dados 


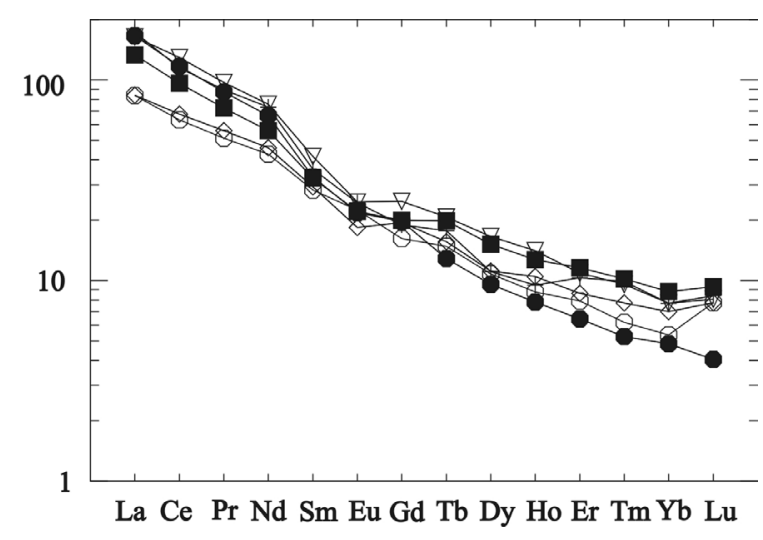

Figura 10 - Padrão de ETR para o Granitóide Barra Alegre. Normalização segundo o condrito de Boynton (1984). Símbolos: O: BA-104; $\diamond$ : BA-34; •: BA-22; +: BA-125; $\nabla: \mathrm{BA}-15$; $\mathbf{\text { 口: BA- }}$ 136.

de granitos do Cinturão Lachland, Austrália, Chappell \& White (2001) vislumbraram que ocorre sobreposição de alguns parâmetros químicos entre granitos tipo I e $\mathrm{S}$ (e.g., campos tipo I e $\mathrm{S}$ nos gráficos binários $\mathrm{K}_{2} \mathrm{O} x$ $\mathrm{Na}_{2} \mathrm{O}$ e FeOt x CaO, valores de $\mathrm{A} / \mathrm{CNK}$ entre 1,0 e 1,1 e razões isotópicas ${ }^{87} \mathrm{Sr} /{ }^{86} \mathrm{Sr}$ variando de 0,704 a 0,712 para granitos do tipo I e 0,708 a 0,717 para granitos do tipo S) e que a relação quase linear nos diagramas de variação é estabelecida preferencialmente para suítes tipo I de baixa temperatura. Características de campo e mineralógicas/petrográficas são apontadas pelos autores como importantes aspectos distintivos. Granitos do tipo S vão apresentar enclaves de rochas metassedimentares e do tipo I principalmente enclaves de rochas contendo hornblenda, como ocorre no Granitóide Barra Alegre. Minerais aluminosos, como muscovita, granada e cordierita são observados nos granitos do tipo $\mathrm{S}$ e hornblenda é importante mineral marcador de granitos do tipo I. Aspectos petrográficos como biotita com pleocroísmo variando de palha a marrom e apatita preferencialmente como inclusões em biotita e hornblenda são descritos por Chappell \& White (2001) como características de granito do tipo I, similar ao que é observado no Granitóide Barra Alegre.

GEOCRONOLOGIA A idade mínima de cristalização do Granitóide Barra Alegre foi calculada com base nas razões ${ }^{207} \mathrm{~Pb} /{ }^{206} \mathrm{~Pb}$, obtidas pelo método de evaporação de $\mathrm{Pb}$ de monocristais de zircão, visto que esta fornece a idade aparente ${ }^{207} \mathrm{~Pb} /{ }^{206} \mathrm{~Pb}$ do grão analisado. A análise foi realizada no Laboratório de Geologia Isotópica da Universidade Federal do Pará, utilizando-se um espectrômetro de massa de termo-ionização Finningan MAT 262. O procedimento seguiu a metodologia desenvolvida por Kober $(1986,1987)$ e a aquisição de dados foi efetuada de modo dinâmico, utilizando-se o sistema de contador de ions. A intensidade do sinal de $\mathrm{Pb}$ foi medida na seqüência de massa ${ }^{206} \mathrm{~Pb},{ }^{207} \mathrm{~Pb},{ }^{208} \mathrm{~Pb}$, ${ }^{206} \mathrm{~Pb},{ }^{207} \mathrm{~Pb}$ e ${ }^{204} \mathrm{~Pb}$ ao longo de 10 varreduras, definindo cinco blocos de dados, cada um deles com no máximo
18 razões ${ }^{207} \mathrm{~Pb} /{ }^{206} \mathrm{~Pb}$, totalizando cerca de 90 razões ${ }^{207} \mathrm{~Pb} /{ }^{206} \mathrm{~Pb}$. Em geral, a razão ${ }^{207} \mathrm{~Pb} /{ }^{206} \mathrm{~Pb}$ foi medida em três etapas de evaporação nas temperaturas de $1450^{\circ} \mathrm{C}$, $1500^{\circ} \mathrm{C}$ e $1550^{\circ} \mathrm{C}$. Excepcionalmente, o grão BALEG-2 apresentou $\mathrm{Pb}$ radiogênico suficiente para uma leitura a $1580^{\circ} \mathrm{C}$. Geralmente, a razão média ${ }^{207} \mathrm{~Pb} /{ }^{206} \mathrm{~Pb}$ obtida na etapa de evaporação de mais alta temperatura foi utilizada para o cálculo da idade do zircão.

As idades aparentes ${ }^{207} \mathrm{~Pb} /{ }^{206} \mathrm{~Pb}$ foram calculadas com uma incerteza de $2 \sigma$ e, naqueles blocos onde a razão ${ }^{204} \mathrm{~Pb} /{ }^{206} \mathrm{~Pb}$ era inferior a 0,0004 , a correção do $\mathrm{Pb}$ comum foi feita mediante a utilização do modelo de evolução do $\mathrm{Pb}$ na Terra em estágio duplo proposto por Stacey \& Kramers (1975), a partir da razão ${ }^{204} \mathrm{~Pb} /{ }^{206} \mathrm{~Pb}$. Foram descartadas do cálculo da idade as leituras onde a razão ${ }^{204} \mathrm{~Pb} /{ }^{206} \mathrm{~Pb}$ foi superior a 0,0004 .

Os cristais de zircão do Granitóide Barra Alegre foram separados da amostra BA-15 (porção NE do corpo) utilizando-se técnicas tradicionais, que envolvem trituração, pulverização e a subseqüente concentração dos cristais de zircão em bateia. Do concentrado gerado foi retirada a fase magnética através de ímã de mão, e em seguida processado no separador isomagnético Frantz e em bromofórmio. A seleção final dos cristais de zircão foi efetivada com o auxílio de lupa binocular.

Os zircões utilizados no cálculo da idade do Granitóide Barra Alegre tinham formas prismáticas alongadas ou curtas e bi-terminadas (proporções entre largura e comprimento variando entre $1 \times 2$ e $1 \times 4)$, eram incolores a amarelados, transparentes a levemente translúcidos e possuíam raras inclusões e fraturas.

Foram analisados 7 cristais de zircão do Granitóide Barra Alegre, dos quais um foi eliminado do cálculo da idade por ter sido considerado como possível cristal herdado (Baleg-1) e um segundo (Baleg-7) por apresentar ${ }^{204} \mathrm{~Pb} /{ }^{206} \mathrm{~Pb}$ superior a 0,0004 . Além disso, um cristal foi eliminado do cálculo subjetivamente (Baleg-3). Para o cálculo da idade final foram utilizados quatro cristais (Baleg-2, 4, 5, 6), que forneceram um total de 256 razões ${ }^{207} \mathrm{~Pb} /{ }^{206} \mathrm{~Pb}$ e uma idade mínima de cristalização de $579 \pm 3$ Ma (Tab. 3 e Fig. 11). No caso do zircão considerado como herdado (Baleg-1), obtevese um único bloco com idade de 625 土 $30 \mathrm{Ma}$.

CONSIDERAÇÕES FINAIS Estudos geológicos sobre granitóides porfiríticos deformados, particularmente aqueles relacionados ao evento orogenético $\mathrm{Ri}$ beira, têm sido recentemente relatados na literatura (e.g. Machado et al. 1996, Junho et al. 1999, Pereira et al. 2001 a, 2001b, Janasi et al. 2001, Mendes et al. 2006). Os corpos pesquisados, denominados Serra do Lagarto, Maromba, Pedra Selada, Funil, Marins, Mendanha, Ibiúna e Rio Turvo, possuem características petrográficas e geoquímicas que permitiram aos autores relacioná-los a um magmatismo cálcio-alcalino do tipo I (excetuando o granitóide Rio Turvo, do tipo-S - Machado et al. 1996). Analogamente, possuem idades de cristalização entre ca. $610 \mathrm{Ma}$ e $580 \mathrm{Ma}$, o que os situam como corpos posicionados/cristalizados concomitantemente 
Tabela 3 - Dados ${ }^{207} \mathrm{~Pb} /{ }^{206} \mathrm{~Pb}$ para cristais de zircão do Granitóide Barra Alegre. Erro como $2 \sigma$.

\begin{tabular}{|c|c|c|c|c|c|c|c|c|c|c|c|c|}
\hline Zircão & $\begin{array}{l}\text { Temp. } \\
\left({ }^{\circ} \mathrm{C}\right)\end{array}$ & $\begin{array}{c}\text { Razões } \\
* *\end{array}$ & ${ }^{204} \mathrm{~Pb} /{ }^{206} \mathrm{~Pb}$ & $2 \sigma$ & ${ }^{208} \mathrm{~Pb} /{ }^{206} \mathrm{~Pb}$ & $2 \sigma$ & ${ }^{207} \mathrm{~Pb} /{ }^{206} \mathrm{~Pb}$ & $2 \sigma$ & $\begin{array}{c}\left({ }^{207} \mathrm{~Pb} / 206 \mathrm{~Pb}\right) \\
\mathrm{c}\end{array}$ & $2 \sigma$ & $\begin{array}{l}\text { Idade } \\
\text { (Ma) }\end{array}$ & $2 \sigma$ \\
\hline BALEG/1 & $\begin{array}{l}* 1450 \\
* 1500 \\
\end{array}$ & $\begin{array}{c}0 / 8 \\
0 / 16\end{array}$ & $\begin{array}{l}0,000031 \\
0,000000 \\
\end{array}$ & $\begin{array}{c}14 \\
0 \\
\end{array}$ & $\begin{array}{l}0,07740 \\
0,08462\end{array}$ & $\begin{array}{l}364 \\
179\end{array}$ & $\begin{array}{l}0,05835 \\
0,06059\end{array}$ & $\begin{array}{l}87 \\
84\end{array}$ & $\begin{array}{l}0,05790 \\
0,06058\end{array}$ & $\begin{array}{l}89 \\
85\end{array}$ & $\begin{array}{l}526 \\
625\end{array}$ & $\begin{array}{l}34 \\
30\end{array}$ \\
\hline BALEG/2 & $\begin{array}{l}1450 \\
1500 \\
1580\end{array}$ & $\begin{array}{l}32 / 32 \\
34 / 34 \\
12 / 12 \\
\end{array}$ & $\begin{array}{l}0,000022 \\
0,000009 \\
0,000071\end{array}$ & $\begin{array}{l}4 \\
2 \\
8 \\
\end{array}$ & $\begin{array}{l}0,09531 \\
0,10090 \\
0,10395\end{array}$ & $\begin{array}{l}132 \\
26 \\
46\end{array}$ & $\begin{array}{l}0,05951 \\
0,05940 \\
0,06007\end{array}$ & $\begin{array}{l}13 \\
10 \\
55\end{array}$ & $\begin{array}{l}0,05919 \\
0,05926 \\
0,05896\end{array}$ & $\begin{array}{l}17 \\
11 \\
37\end{array}$ & $\begin{array}{l}574 \\
577 \\
566\end{array}$ & $\begin{array}{c}6 \\
4 \\
14 \\
\end{array}$ \\
\hline BALEG/3 & *1500 & $0 / 6$ & 0,000316 & 16 & 0,09342 & 64 & 0,06127 & 52 & 0,05667 & 57 & 479 & 22 \\
\hline BALEG/4 & $\begin{array}{l}* 1450 \\
1500 \\
1550\end{array}$ & $\begin{array}{c}0 / 40 \\
38 / 38 \\
32 / 32 \\
\end{array}$ & $\begin{array}{l}0,000045 \\
0,000035 \\
0,000053\end{array}$ & $\begin{array}{l}2 \\
7 \\
9\end{array}$ & $\begin{array}{l}0,09560 \\
0,11454 \\
0,12541\end{array}$ & $\begin{array}{l}115 \\
28 \\
67\end{array}$ & $\begin{array}{l}0,05969 \\
0,05978 \\
0,06010\end{array}$ & $\begin{array}{c}8 \\
11 \\
12\end{array}$ & $\begin{array}{l}0,05904 \\
0,05926 \\
0,05927\end{array}$ & $\begin{array}{c}9 \\
11 \\
13\end{array}$ & $\begin{array}{l}569 \\
577 \\
577\end{array}$ & $\begin{array}{l}3 \\
4 \\
5\end{array}$ \\
\hline BALEG/5 & $\begin{array}{c}\# 1450 \\
1500 \\
1550 \\
\end{array}$ & $\begin{array}{c}0 / 32 \\
32 / 32 \\
36 / 36 \\
\end{array}$ & $\begin{array}{l}0,000668 \\
0,000069 \\
0,000030\end{array}$ & $\begin{array}{c}15 \\
5 \\
4 \\
\end{array}$ & $\begin{array}{l}0,09456 \\
0,09568 \\
0,10456 \\
\end{array}$ & $\begin{array}{c}115 \\
61 \\
26 \\
\end{array}$ & $\begin{array}{l}0,06806 \\
0,06028 \\
0,05987\end{array}$ & $\begin{array}{l}36 \\
23 \\
11 \\
\end{array}$ & $\begin{array}{l}0,05886 \\
0,05944 \\
0,05948 \\
\end{array}$ & $\begin{array}{l}30 \\
18 \\
12 \\
\end{array}$ & $\begin{array}{l}562 \\
584 \\
585 \\
\end{array}$ & $\begin{array}{c}11 \\
6 \\
4 \\
\end{array}$ \\
\hline BALEG/6 & $\begin{array}{c}* 1450 \\
1500\end{array}$ & $\begin{array}{c}0 / 36 \\
40 / 40 \\
\end{array}$ & $\begin{array}{l}0,000026 \\
0,000017\end{array}$ & $\begin{array}{l}4 \\
3 \\
\end{array}$ & $\begin{array}{l}0,07700 \\
0,09225\end{array}$ & $\begin{array}{l}82 \\
32 \\
\end{array}$ & $\begin{array}{l}0,05936 \\
0,05955\end{array}$ & $\begin{array}{l}24 \\
12 \\
\end{array}$ & $\begin{array}{l}0,05904 \\
0,05934\end{array}$ & $\begin{array}{l}24 \\
12 \\
\end{array}$ & $\begin{array}{l}569 \\
580\end{array}$ & $\begin{array}{l}9 \\
4 \\
\end{array}$ \\
\hline BALEG/7 & $\begin{array}{l}\# 1450 \\
\# 1500\end{array}$ & $\begin{array}{l}0 / 12 \\
0 / 30\end{array}$ & $\begin{array}{l}0,001239 \\
0,000636\end{array}$ & $\begin{array}{c}208 \\
38\end{array}$ & $\begin{array}{l}0,15818 \\
0,17298\end{array}$ & $\begin{array}{l}85 \\
46\end{array}$ & $\begin{array}{l}0,08006 \\
0,06870\end{array}$ & $\begin{array}{l}16 \\
51\end{array}$ & $\begin{array}{l}0,06217 \\
0,05948\end{array}$ & $\begin{array}{c}296 \\
64\end{array}$ & $\begin{array}{l}680 \\
585\end{array}$ & $\begin{array}{c}102 \\
23\end{array}$ \\
\hline & \multicolumn{10}{|c|}{ Idade calculada } & 579 & 3 \\
\hline
\end{tabular}

Barra Alegre

Idade $=579 \pm 3 \mathrm{Ma}$

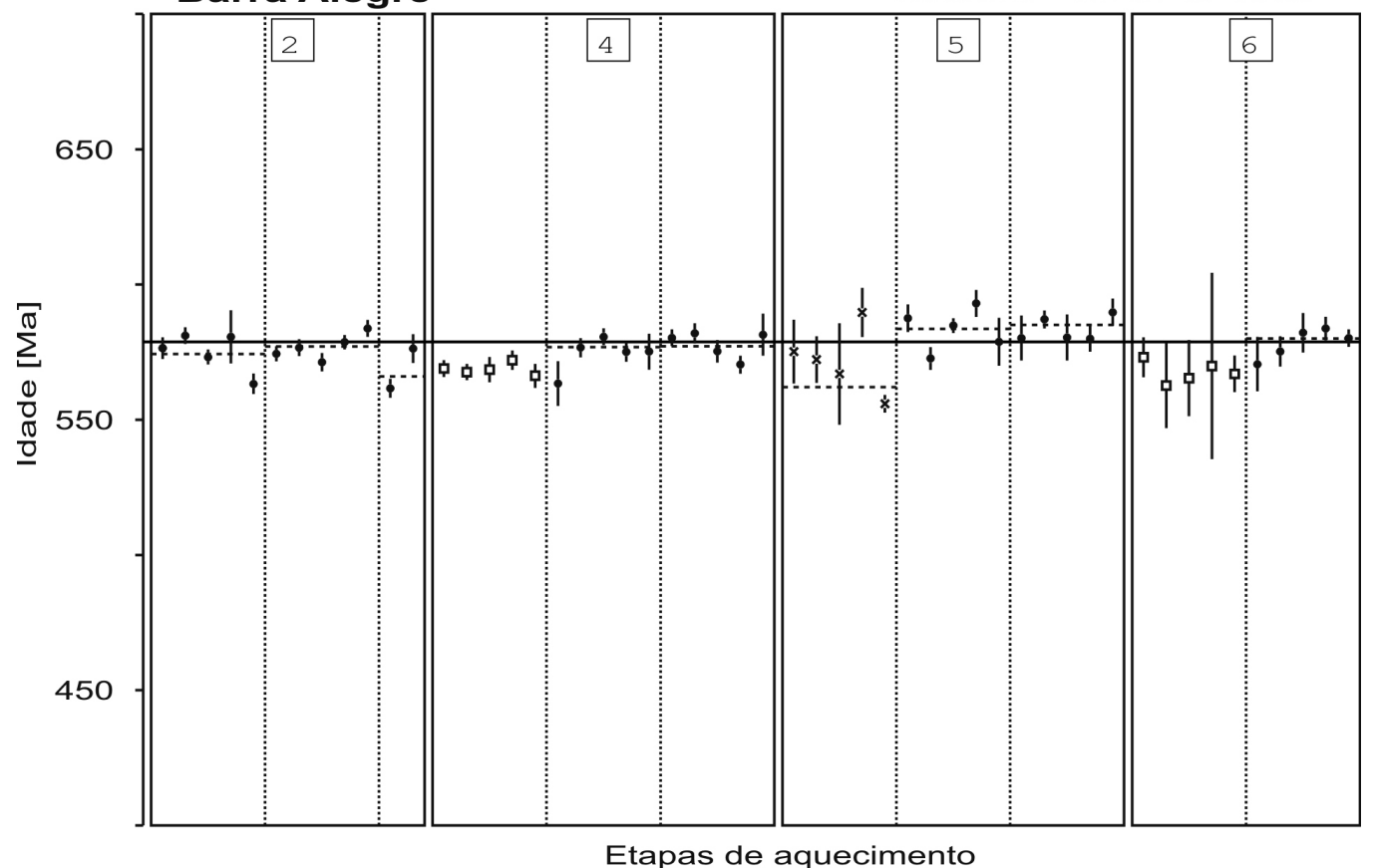

Figura 11 - Diagrama Idade (Ma) x Etapa de Evaporação dos cristais de zircão do Granitóide Barra Alegre. Círculos: bloco de razões isotópicas utilizadas para o cálculo da idade; Quadrados: bloco eliminado por aumento ou diminuição das razões ${ }^{207} \mathrm{~Pb} /{ }^{206} \mathrm{~Pb}$; Cruzes: bloco rejeitado devido a razões ${ }^{204} \mathrm{~Pb} /{ }^{206} \mathrm{~Pb}>0.0004$. Erro como $2 \sigma$.

à fase sin-colisional da porção centro-sul do orógeno Ribeira ( 610 - 560 Ma; Trouw et al 2000, Campos Neto 2000). O granitóide Barra Alegre se insere em um contexto geoquímico-geocronológico similar e é mais um exemplo do magmatismo cálcio-alcalino de idade sin-colisional, e gerador de tipos porfiríticos, do Seg- mento Central da Faixa Ribeira.

Duas litofácies foram definidas no Granitóide Barra Alegre: a fácies Barra Alegre e a fácies Carijó, que foi definida a partir de deformação heterogênea sobre a fácies Barra Alegre. Tramas de natureza magmática estão amplamente distribuídas na fácies Barra 
Alegre e tramas secundárias se concentram sobretudo nas zonas de borda, onde predominam os litotipos da fácies Carijó, que apresentam apenas feições primárias reliquiares, como feldspatos subédricos. Traçando-se um paralelo entre elas, a fácies Barra Alegre apresenta textura megaporfirítica e deformação incipiente e a fácies Carijó fenocristais milimétricos de forma amendoada e xistosidade bem desenvolvida. A preservação das feições ígneas na fácies Barra Alegre provavelmente só foi possível porque as atitudes das estruturas de origem tectônica não foram muito discordantes das atitudes das estruturas de origem primária, ou seja, os processos de recristalização não afetaram os hábitos dos fenocristais nesta litofácies. A diferente composição da matriz, tonalítica/granodiorítica na fácies Barra Alegre e granítica na fácies Carijó, é aqui interpretada como o resultado de intensa recristalização e geração de novos grãos a partir dos megacristais de microclina.

As obsevações microscópicas possibilitaram o reconhecimento de elementos texturais básicos nos grãos de quartzo e feldspato. A redução da granulometria e as mudanças de composição na matriz, provocadas em parte pela incorporação de novos grãos recristalizados a partir dos fenocristais, são observadas em ambas as litofácies, sobretudo na fácies Carijó. Ao se comparar com as proposições de Paschier \& Trouw (2005) para a geração de microtexturas deformacionais em rochas quartzo-feldspáticas, possivelmente tais modificações foram geradas por recristalização dinâmica em condições de médio grau, fruto da associação entre os mecanismos Grain Boundary Migration (GBM) e rotação de subgrãos (SRR). A trama poligonal, muito comum em agregados de grãos na matriz, é o indício de que processos de recristalização estática em médio grau como Grain Boundary Area Reduction (GBAR) também tiveram um importante papel na evolução faciológica do corpo (Matos et al. 2005, Duffles-Teixeira 2005).

As lineações e foliações têm direção predominantemente NE-SW e tendem a ser subparalelas aos contatos do corpo, sugerindo a forma de um sill. Levando-se em consideração o fato da lineação de fluxo magmático ser aproximadamente concordante com a lineação de estiramento, esta disposição poderia ser interpretada como resultante de um alojamento condicionado por um campo de tensões tectônicas caracterizado por estiramento principal na direção NE-SW.
As análises químicas do Granitóide Barra Alegre evidenciam um conjunto rochoso de variação composicional estreita, geoquimicamente classificado como granodiorito. Padrões de ETR relativamente homogêneos, moderadamente fracionados e com suave anomalia negativa de Eu, sugerem a cogeneticidade das rochas estudadas. A falta de correlação entre os teores de ETR e de $\mathrm{SiO}_{2}$ pode ser reflexo do controle exercido por fases minerais acessórias (apatita, zircão, allanita, hornblenda e titanita) na concentração de ETR. Os diagramas de Harker ilustram a tendência ao decréscimo dos teores de $\mathrm{TiO}_{2}, \mathrm{Al}_{2} \mathrm{O}_{3}, \mathrm{Fe}_{2} \mathrm{O}_{3}, \mathrm{CaO}, \mathrm{Na}_{2} \mathrm{O}, \mathrm{K}_{2} \mathrm{O}, \mathrm{Rb}$ e $\mathrm{Sr}$ com o aumento do teor de $\mathrm{SiO}_{2}$. A variação dos conteúdos de elementos maiores permitiu inferir uma assinatura cálcio-alcalina de alto $\mathrm{K}$ para a seqüência estudada, sendo ela pertencente ao grupo magnesiano e fracamente peraluminoso de Frost et al. (2001). Os parâmetros geoquímicos sugeridos por Chappell \& White $(1974,2001)$ não são conclusivos quanto a um caráter tipo I ou S para os litotipos estudados. Entretanto, avaliando-se em conjunto com parâmetros de campo e mineralógicos/petrográficos propostos pelos autores, conclui-se que o Granitóide Barra Alegre pode ser classificado como sendo do tipo I (é importante enfatizar que os termos mais evoluídos de seqüências ácidas tipo I podem ser levemente peraluminosos).

Razões ${ }^{207} \mathrm{~Pb} /{ }^{206} \mathrm{~Pb}$ obtidas por evaporação de $\mathrm{Pb}$ de monocristais de zircão forneceram uma idade mínima de cristalização de $579 \pm 3$ Ma para o Granitóide Barra Alegre. A idade obtida indica um posicionamento sin-tectônico para o corpo, consistente com as feições deformacionais macro e microscópicas observadas e descritas neste trabalho. Em síntese, o seu posicionamento, e subseqüente resfriamento, deve ter sido contemporâneo ao principal evento deformacional na região, ocorrido entre 590 e $570 \mathrm{Ma}$. Dentro do modelo geotectônico atualmente proposto para a estruturação do Segmento Central da Faixa Móvel Ribeira, o Granitóide Barra Alegre encontra-se inserido no Domínio Costeiro e associa-se ao episódio ( $\sin )$ colisional I definido por Heilbron \& Machado (2003).

Agradecimentos À FAPERJ (Fundação de Amparo à Pesquisa do Rio de Janeiro) e ao CNPq por auxílio financeiro e bolsas concedidas. Aos revisores da RBG, Valdecir Janasi e um revisor anônimo, que muito contribuíram com valiosas críticas e sugestões ao manuscrito.

\section{Referências}

Boynton W.V. 1984. Cosmochemistry of the rare earth element: meteorite studies. In: P. Henderson (Ed.) Rare Earth Element Geochemistry. Amsterdan, Elsevier, p. 63-114.

Campos Neto M.C. 2000. Orogenic Systems from Southwestern Gondwana: an approach to Brasiliano-Pan African Cycle and Orogenic Collage in Southeastern Brazil. In: U. Cordani, E. Milani, A.Thomaz Filho, D. Campos
(Eds.) Tectonic Evolution of South America. Rio de Janeiro, CPRM, p. 335-365.

Chappell B. W. \& White A. J. R. 1974. Two Contrasting Granite Types. Pacific Geology, 8:173-174.

Chappell B. W. \& White A. J. R. 2001. Two Contrasting Granite Types: 25 years later. Australian Journal of Earth Sciences, 48(4):489-499.

Clarke D.B. 1981. The mineralogy of peraluminous granites: 
a review. Canadian Mineralogist, 19(1):1-17.

Cox K.G., Bell J.D., Pankhurst R.J. 1979. The interpretation of igneous rocks. London, Unwin Hyman Ltd., 450p.

Debon F. \& Le Fort P. 1983. A chemical-mineralogical classification of common plutonic rocks and associations. Transactions of the Royal Society of Edinburgh Earth Sciences, 73:135-149.

Duffles-Teixeira P. 2005. Caracterização geológica, petrográfica e geoquímica do granitóide Barra Alegre, município de Bom Jardim, RJ. Dissertação de Mestrado, Igeo/ UFRJ, 76 p.

Fonseca M.J.G. 1998. Mapa Geológico do Estado do Rio de Janeiro, escala 1:400.000. Texto Explicativo. DNPM/ MME Rio de Janeiro, 141 p.

Frost B.R., Barnes C.G., Collins W.J., Arculus R.J., Ellis D.J., Frost C.D. 2001. A geochemical classification for granitic rocks. Journal of Petrology, 42 (11):2033-2048.

Heilbron M. \& Machado N. 2003. Timing of terrane accretion in the Neoproterozoic-Eopaleozoic Ribeira orogen (SE Brazil). Precambrian Research, 125:87-112.

Irvine T.N. \& Baragar W.R.A. 1971. A guide to the chemical classification of the common volcanic rocks. Canadian Journal of Earth Sciences, 8(5):523-548.

Janasi V.A., Leite R.J., Van Schmus W.R. 2001. U-Pb chronostratigraphy of the granitic magmatism in the Agudos Grandes Batholith (west of São Paulo, Brazil) - implications for the evolution of the Ribeira Belt. Journal of South American Earth Sciences. 14(4):363-376.

Junho M.C.B. 1993. Granitóides Brasilianos da Região Central do Estado do Rio de Janeiro - Geoquímica Preliminar. An. Acad. Bras. Ci., 65(2):161-179.

Junho M.C.B., Heilbron M., Valeriano C.M. 1999. Porphyritic I-type syntectonic granites and related rocks, Ribeira Mobile Belt, southwestern Rio de Janeiro state, Brazil. An. Acad. bras. Ci., 71(4-I):631-647.

Kober B. 1986. Whole-grain evaporation for ${ }^{207} \mathrm{~Pb} / 206 \mathrm{~Pb}$ age investigations on single zircons using a double filament thermal ion source. Contributions to Mineralogy and Petrology, 93(4):482-490.

Kober B. 1987. Single-zircon evaporation combined with $\mathrm{Pb}^{+}$emitter bedding for ${ }^{207} \mathrm{~Pb} /{ }^{206} \mathrm{~Pb}$ age investigations using thermal ion mass spectrometry, and implications to zirconology Contributions to Mineralogy and Petrology, 96(1):63-71.

Kosaka K., Shimizu M., Takizawa S. 1999. Delineation of deformation grades of low-strain granitoids using assemblages of elementary deformation textures. Journal of Structural Geology, 21:1525-1534.

Le Maitre R.W. 1989. A classification of igneous rocks and glossary of terms. Oxford, Blackwell, 193p.

Machado N., Valladares C., Heilbron M., Valeriano C. 1996. $\mathrm{U}-\mathrm{Pb}$ geochronology of the central Ribeira belt (Brazil) and implications for the evolution of the Brazilian Orogeny. Precambrian Reserch, 79(3-4):347-361.

Matos G.C., Medeiros F.F., Mendes J.C. 2005. Faciologia do Granito Barra Alegre, região serrana do Estado do RJ, e sua relação com a tectônica regional. In: $\mathrm{SBG}$, Simpósio Nacional de Estudos Tectônicos (SNET), 10, Boletim de Resumos Expandidos, p. 479-481.

Mendes J.C., Junho M.B, Ghizi A. 2004. Diorites and hor- nblendite enclaves at Sumidouro, RJ, Central Ribeira Belt. Revista Brasileira de Geociências, 34(1):79-86.

Mendes J. C., Ávila C. A., Pereira R. M., Heilbron M., Moura C. V. $2006 .{ }^{207} \mathrm{~Pb} /{ }^{206} \mathrm{~Pb}$-ages of zircons from syn-collisional I-type porphyritic granites of the central Ribeira belt, SE Brazil. Gondwana Research, 9(3):326-336.

Nockolds S.R. \& Allen R. 1954. The geochemistry of some igneous rock series. Part II. Geochem. Cosmochim. Acta, 5:245-285.

Passchier N. \& Trouw R. A. J. 2005. Micro-tectonics. Springer-Verlag Berlin Heidelberg, Germany, 2a ed, 366 p.

Paterson S.R., Vernon R.H., Tobisch O.T. 1989. A review of criteria for the identification of magmatic and tectonic foliations in granitoids. Journal of Structural Geology, 11(3):349-363.

Peccerillo A. \& Taylor S.R. 1976. Geochemistry of Eocene calc-alkaline volcanic rocks from the Kastamonu area, northern Turkey. Contrib. Mineral. Petrol., 58:63-81.

Pereira R.M., Ávila C.A., Moura C.V. 2001a. Geologia da região entre Resende e São José do Barreiro e idade ${ }^{207} \mathrm{~Pb} /{ }^{206} \mathrm{~Pb}$ do Granito do Funil, segmento central da Faixa Ribeira (RJ-SP), Brasil. Geociências, 20(1/2):37-48.

Pereira R.M., Ávila C.A., Moura C.V., Roig L.R. 2001b. Geologia e geoquímica do Granito Mendanha e do Granitóide Marins e idade ${ }^{207} \mathrm{~Pb} /{ }^{206} \mathrm{~Pb}$ (por evaporação de zircão) do Granito Mendanha, Faixa Ribeira Central, Estado de São Paulo. Geociências, 20(1/2):49-60.

Pinto C.P. 1980. Projeto Carta Geológica do Estado do RJFolhas Anta, Duas Barras, Teresópolis e Nova Friburgo. Belo Horizonte, Geosol - Geologia e Sondagens Ltda., Relatório Final, vol.1.

Schmitt R. S., Trouw R.A.J, Van Schmus W.R., Pimentel M.M. 2004. Late amalgamation in the central part of West Gondwana: new geochronological data and the characterization of a Cambrian orogeny in the Ribeira Belt - SE Brazil. Precambrian Research, 133(1-2):2961.

Shand S.J. 1943. The eruptive rocks. John Wiley, New York, segunda edição. 444p.

Silva L.C., Santos R.A., Delgado I.M., Cunha H.C.S. 2000. Mapa Geológico do Estado do Rio de Janeiro. Rio de Janeiro, CPRM, MME, escala 1:500.000.

Stacey J.S. \& Kramer J.D. 1975. Approximation of terrestrial lead isotope by a two-stage model. Earth and Planetary Science Letters, 26(2):207-221.

Trouw R., Heilbron M., Ribeiro A., Paciullo F., Valeriano C., Almeida J., Tupinambá M., Andreis R. 2000. The Central Segment of the Ribeira Belt. In: U. Cordani, E. Milani, A. Thomaz Filho, D. Campos, (eds.) Tectonic Evolution of South America. Rio de Janeiro, CPRM, p. 287-310.

Tupinambá M. 1999. Evolução Tectônica e Magmática da Faixa Ribeira na Região Serrana do Estado do Rio de Janeiro. Tese de Doutoramento, IG-USP, 222p.

Wilson M. 1991. Igneous Petrogenesis, Harper Collins Acad., 466 p.

Manuscrito AE-037/2006

Recebido em 07 de agosto de 2006 Aceito em 13 de abril de 2007 